\title{
Transition of Care in Paediatric Surgery
}

\section{Current practices and perspectives of paediatric surgeons in Malaysia}

"Shung K. Tan, ${ }^{1}$ Anand Sanmugam, ${ }^{1}$ Mahmoud Danaee, ${ }^{2}$ Tindivanam M. Ramanujam, ${ }^{3}$ Mohan A. Nallusamy, ${ }^{4}$ Zakaria Zahari, ${ }^{5}$ Thambidorai R. Rao ${ }^{1}$

$$
\begin{aligned}
& \text { انتقال الرعاية في جراحة الأطفال } \\
& \text { الممارسات ووجهات النظر الحالية لجراحي الأطفال في ماليزيا لإنيا }
\end{aligned}
$$

شونغ كين تان، أناند سانموجام، محمود دناعي، تندفانام موثورانجام رامانوجام، موهـان أروناسالام نالوسامي، زكريـا زاهـاري، ثامبيدوراي راجيندراراو

ABSTRACT: Objectives: Transition of care (TOC) from paediatric to adult care is still at an early stage in Malaysia. This study aimed to explore current practices and perspectives regarding TOC among paediatric surgeons in Malaysia. Methods: This study was carried out between June and December 2017. All 48 paediatric surgeons currently working in Malaysia were invited to participate in a questionnaire-based survey to assess demographic characteristics and practices and perspectives regarding TOC. Results: A total of 38 paediatric surgeons participated in the survey (response rate: 79.2\%). Overall, 97.4\% did not have an organised TOC model in their institution, with most (65.8\%) caring for paediatric patients with complex surgical conditions until adulthood. Although the majority (86.8\%) felt that care should be transitioned to adult surgeons with appropriate credentials, most surgeons $(84.2 \%)$ nevertheless preferred to be involved in the management of adolescent patients after transition. However, there was no consensus regarding the most suitable age to begin the transition. Years of experience as a paediatric surgeon and place of practice did not affect overall TOC practice scores $(P>0.050$ each). The presence of adult comorbidities was considered the most common reason to initiate TOC $(81.6 \%)$, while the lack of TOC guidelines was perceived to be the greatest barrier (84.2\%). Conclusion: This study provides a better understanding of TOC from the point of view of paediatric surgeons in Malaysia. However, further studies involving other stakeholders (i.e. patients and adult surgeons) are needed to help formulate a suitable and successful TOC model in this setting.

Keywords: Transition to Adult Care; Pediatrics; Adolescents; Surgery; Attitudes; Professional Practice; Malaysia.

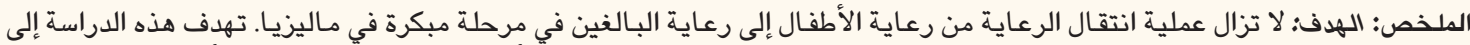

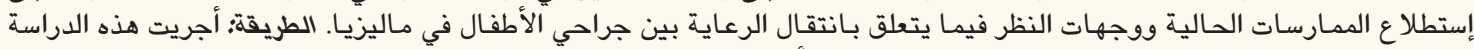

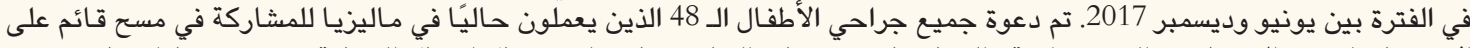

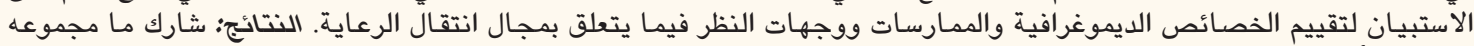

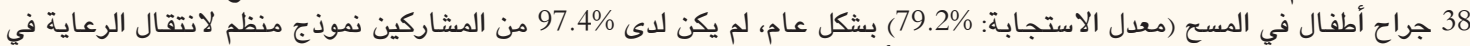

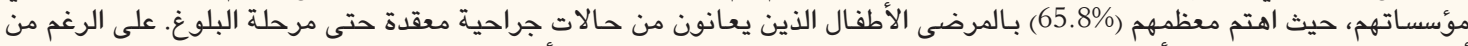

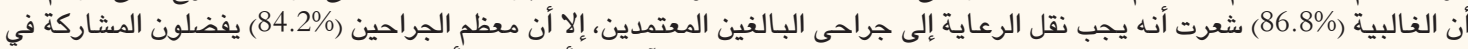

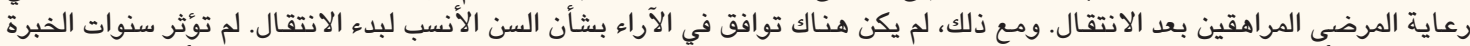

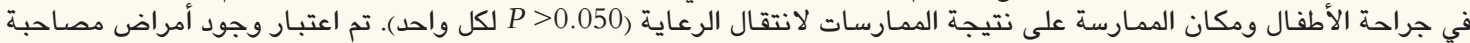

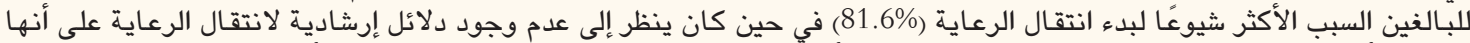

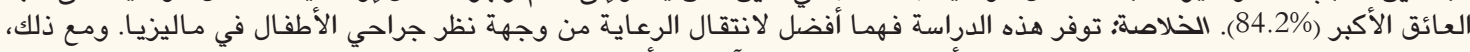

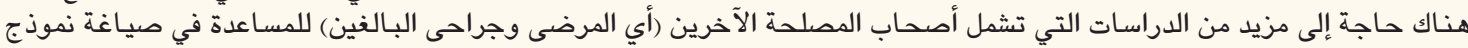

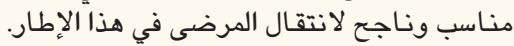

الكلمات المفتاحية: الانتقال إلى رعاية البالغين؛ طب الأطفال؛ المراهقين؛ الجراحة؛ الاتجاهـات؛ الممارسة المهنية؛ ماليزيا.

\section{ADVANCES IN KNOWLEDGE}

To the best of the authors' knowledge, this is the first study to evaluate paediatric surgeons' perspectives regarding transition of care (TOC) in Malaysia

The results of this survey suggest that there is a lack of proper guidelines in Malaysian institutions when transitioning adolescents with complex surgical conditions to adult care.

\section{Application to Patient Care}

The preliminary results of this study may help to initiate dialogue among stakeholders in Malaysia and encourage efforts to improve TOC guidelines for this group of patients. 
A DOLESCENTS WITH COMPLEX MEDICAL OR surgical conditions usually have ongoing medical issues which require regular followup, monitoring and treatment; however, up to 20-25\% may drop out or become lost to follow-up soon after being discharged from paediatric care due to a lack of appropriate organisation and planning when transitioning to adult care. ${ }^{1,2}$ This can lead to increased morbidity, mortality and poor long-term prognosis and quality of life. ${ }^{3}$

Transition of care (TOC) refers to the process whereby adolescents and young adults with chronic physical and medical conditions are transferred from child-centred to adult-oriented healthcare systems. ${ }^{4}$ The objective is to provide continuous and uninterrupted healthcare appropriate to the developmental age of the patient in order to maximise lifelong functioning. ${ }^{5}$ Transition programmes help to improve follow-up and result in better control of acute and chronic complications. ${ }^{6}$ The benefits of TOC models have been substantiated in various medical subspecialties, including paediatric cardiology, spina bifida, organ transplantation and adolescent urology units. $^{7-10}$

Although TOC is practiced in many developed countries such as the USA, Canada, UK and Australia, its usage in South-East Asian nations is still in its infancy. ${ }^{11-13}$ While healthcare providers in this region agree on the need for TOC programmes, actual TOC guidelines are still either not established or under-developed. This results in paediatricians caring for adolescent patients well into adulthood and the eventual transfer to adult care occurring in an abrupt, disorganised and ad hoc manner. ${ }^{14,15}$

Over the past three decades, surgical care for infants with congenital surgical conditions in Malaysia has improved significantly, resulting in increased survival among infants with conditions such as oesophageal and bowel atresia, anorectal anomalies and Hirschsprung's disease. ${ }^{16-18}$ However, without a proper plan for their transition to adult care, adolescents and young adults with complex surgical conditions, who present to surgeons specialising in adult care, can often be referred back to paediatric surgeons. As such, the practices and opinions of paediatric surgeons regarding TOC are an essential first step in ensuring a smooth transition to adult care. Therefore, this study aimed to explore current practices and perspectives regarding TOC among paediatric surgeons in Malaysia.

\section{Methods}

This study took place between June and December 2017. A universal sampling method was used to target all 48 paediatric surgeons in Malaysia currently practicing in public, university and private hospitals. A self-administered English language questionnaire was designed based on published research regarding TOC. ${ }^{14}$ The questionnaire was distributed either via e-mail $(39.6 \%)$ or in person $(60.4 \%)$ to all paediatric surgeons. Non-responders to the initial survey request were reminded after one month to improve the response rate.

During the survey design stage, a literature review was conducted on the topic of TOC, followed by a discussion with a focus group composed of four paediatric surgeons and a statistician. Survey questions were grouped into three categories. The first section of the survey assessed the participants' demographic characteristics, while current practices and perspectives regarding TOC for adolescents with complex surgical conditions were evaluated in the second and third sections, respectively. An initial draft of the questionnaire was distributed to the focus group for feedback with revisions made according to their recommendations. Subsequently, a second draft was distributed to medical practitioners from various specialties to evaluate face and content validity. The questionnaire was then finalised after the validation process. Some questions were multiple-choice, for example, some paediatric surgeons indicated that they have adolescent patients whom they managed with adult surgeons or only by themselves.

Overall practice scores were calculated to reflect actual TOC practices in Malaysia. The scores were based on responses to four questions from the survey indicating the existence of TOC practices and supporting facilities. Each question was given a score of either one or zero to indicate answers of "yes" or "no", respectively. Total scores ranged from 0-4, with higher scores representing better practices. Mean practice scores were subsequently correlated to the participants' place of practice and number of years of experience as a paediatric surgeon.

In addition, the paediatric surgeons were asked to evaluate five out of 11 factors which they perceived to be the most significant barriers to establishing an organised TOC procedure in their institution. Participants ranked the five barriers from most to least significant, with one being most significant and five being least significant. Only five barriers were ranked instead of all 11 barriers listed so as to avoid questionnaire fatigue. Subsequently, the rank of each barrier was determined by calculating frequencies and mean scores, with barriers with a higher frequency and a lower mean value being more significant. The five most frequently cited barriers were then listed and ranked according to their mean scores. 


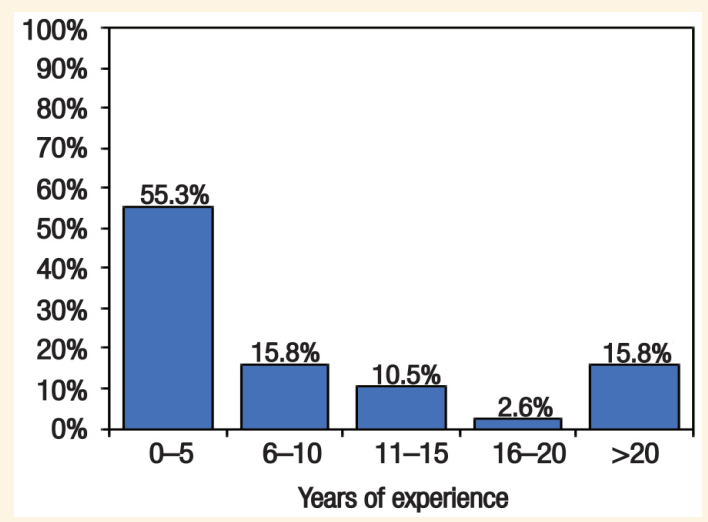

Figure 1: Years of experience among paediatric surgeons in Malaysia $(\mathrm{N}=38)$.

The statistical analysis was performed using the Statistical Package for the Social Sciences (SPSS), Version 22.0 (IBM Corp., Armonk, New York, USA). Demographic data and TOC practices and perspectives were reported using descriptive statistics. Overall practice scores were compared according to place of practice (i.e. public, university-affiliated or private hospitals) using the Kruskal-Wallis oneway analysis of variance non-parametric test since the total numbers of surgeons in each category were unequal. The correlation coefficient between years of experience and overall practice scores was calculated using Spearman's test. A $P$ value of $<0.05$ was deemed statistically significant.

Ethical permission for this study was granted by the Medical Research \& Ethics Committee of the Ministry of Health in Malaysia (\#NMRR-17-903-35519). Informed consent was received from all participants prior to their inclusion in the study.

\section{Results}

A total of 38 paediatric surgeons participated in the study (response rate: 79.2\%). Most worked in the public healthcare system, either in Ministry of Healthaffiliated (76.3\%) or university-affiliated (15.8\%) hospitals; few surgeons worked in private hospitals (7.9\%). Younger surgeons with $0-5$ years of experience were the largest group of respondents (55.3\%), followed by both senior surgeons with $>20$ years of experience and those with 6-10 years of experience (15.8\% each) [Figure 1]. Most surgeons (76.3\%) had prior knowledge of the concept of TOC, usually obtained during postgraduate training, journal research or conference attendance.

With regards to TOC practices, the majority of the participants (97.4\%) did not have an organised TOC model in their institution. In addition, none of the hospitals had a dedicated ward for adolescents

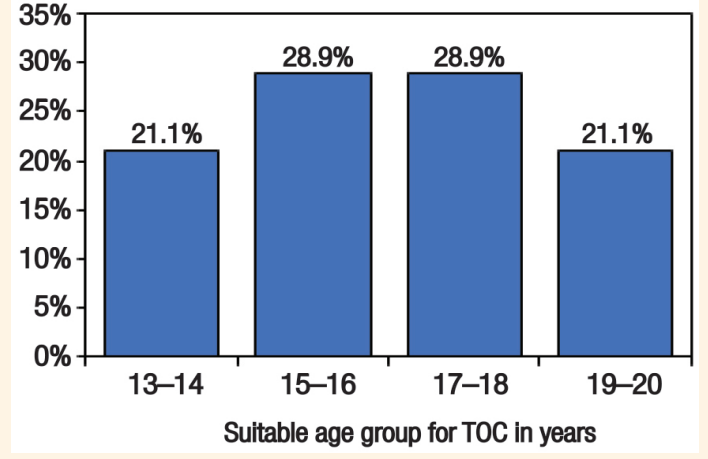

Figure 2: Distribution of opinions regarding the appropriate age to initiate transition of care among paediatric surgeons in Malaysia $(\mathrm{N}=38)$.

TOC = transition of care.

with complex surgical conditions, with such patients usually either admitted to paediatric (57.9\%) or adult (42.1\%) wards. Moreover, most paediatric surgeons (67.6\%) took care of patients with complex surgical conditions until adulthood. The remaining $32.4 \%$ of surgeons discharged patients if they had no active symptoms or did not require active management at that time. The majority of surgeons either managed adolescent patients solely (65.8\%) or in conjunction with adult surgeons (26.3\%). The remaining 13.2\% stated that adult surgeons were the sole healthcare providers for these patients.

In terms of their perspectives on TOC policies, most respondents (63.2\%) thought that written transfer summaries should be endorsed by the consultant or specialist in charge of the patient. The majority (86.8\%) believed there was a need for the receiving team to hold appropriate credentials and privileges to manage this group of patients. However, many surgeons (84.2\%) still felt that it was their obligation to provide consultation and care even after adolescent patients had been transitioned to adult care. Most surgeons (42.1\%) considered that an organised TOC model should be implemented at their institution within the next $3-5$ years, while the remaining $39.5 \%$ and $18.4 \%$ felt that this should be introduced in $\geq 5$ or $1-2$ years, respectively. However, opinions were evenly divided regarding the age group most suitable at which to begin TOC [Figure 2].

The paediatric surgeons were also surveyed regarding initiating factors for TOC. The presence of adult comorbidities (81.6\%) was cited as the most common reason for transferring adolescent patients to adult care, followed by a stable disease process (71.1\%), pregnancy (60.5\%), institutional policies $(44.7 \%)$ and the patient's perceived independence to make their own healthcare decisions (44.7\%). Marriage (26.3\%) and college entry (18.4\%) were deemed the least important transition triggers [Figure 3]. 


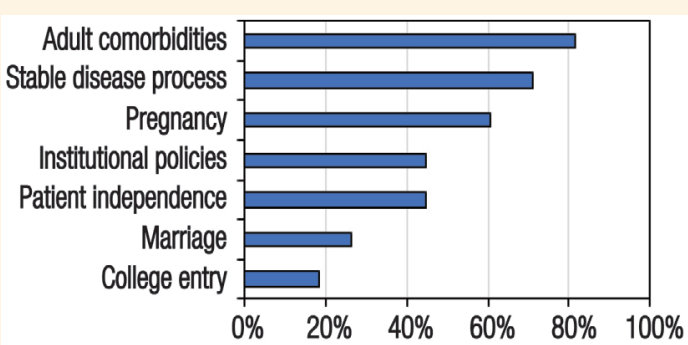

Figure 3: Distribution of triggers that initiate transition of care among paediatric surgeons in Malaysia $(\mathrm{N}=38)$.

Table 1: Perceived barriers to transition of care among paediatric surgeons in Malaysia $(\mathrm{N}=38)$

\begin{tabular}{|c|c|c|}
\hline Barrier & n (\%) & Mean score s $^{*} \pm \mathrm{SD}$ \\
\hline Lack of guidelines & $32(84.2)$ & $2.37 \pm 1.43$ \\
\hline Institutional policies & $21(55.3)$ & $2.38 \pm 1.63$ \\
\hline $\begin{array}{l}\text { Lack of awareness among } \\
\text { healthcare providers }\end{array}$ & $22(57.9)$ & $2.86 \pm 1.04$ \\
\hline $\begin{array}{l}\text { Lack of adult healthcare } \\
\text { providers }\end{array}$ & $19(50)$ & $3.00 \pm 1.29$ \\
\hline $\begin{array}{l}\text { Emotional attachment to } \\
\text { paediatric care providers }\end{array}$ & $22(57.9)$ & $3.27 \pm 1.62$ \\
\hline
\end{tabular}

"Respondents were asked to rank five barriers out of 11 which they perceived to be the most significant, with one being most significant and five being least significant. Barriers with higher frequencies and lower mean scores are of greater significance.

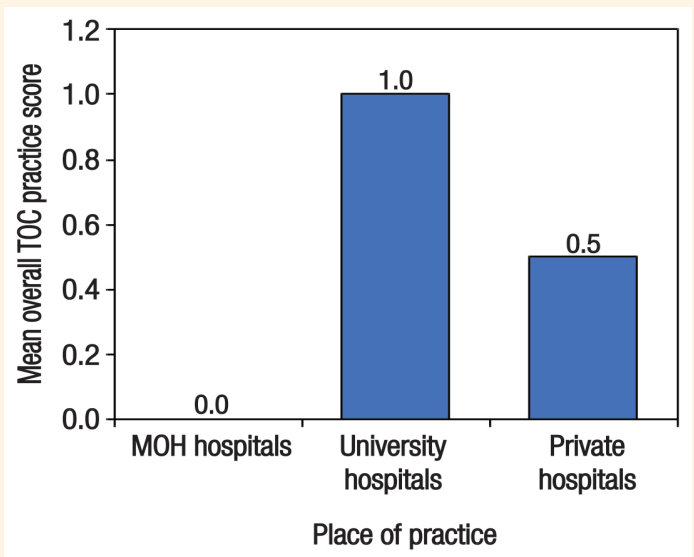

Figure 4: Mean overall transition of care practice scores according to place of practice among paediatric surgeons in Malaysia $(\mathrm{N}=38)$.

$T O C=$ transition of care; $M O H=$ Ministry of Health .

A lack of guidelines was the most frequently cited TOC barrier (84.2\%) and was also deemed most significant by the paediatric surgeons (mean score: $2.37 \pm 1.43$ ). Institutional policies and lack of awareness among healthcare providers were also ranked highly (mean scores: $2.38 \pm 1.63$ and $2.86 \pm 1.04$, respectively). More than half of the respondents (57.9\%) indicated that emotional attachment on the part of the patient/ parents was a barrier to transition, while $50 \%$ cited the lack of adult healthcare providers familiar with paediatric surgical problems [Table 1].

Although paediatric surgeons working in university-affiliated hospitals had higher mean overall practice scores compared to those working in private and public hospitals [Figure 4], these findings were not significant (Kruskal-Wallis value $=0.502 ; P=0.778$ ) . Although there was a weak positive correlation between number of years of experience as a paediatric surgeon and mean overall practice score, this was also not significant $(r=0.157 ; P=0.357)$.

\section{Discussion}

The results of the current study are important as they reflect actual TOC practices and perspectives among the majority of paediatric surgeons currently working in Malaysia. Such information may help to shed more light on the state of TOC and inform future healthcare developments in this region. Importantly, the overall positive responses to this survey show an interest in TOC and a willingness to improve the care of adolescents with complex surgical conditions among this group of healthcare practitioners. Nevertheless, as can be observed in the current study, TOC is still not widely practiced among paediatric surgeons in Malaysia. The majority of respondents did not have an organised model of transition or a specialised clinic or ward for adolescent patients. Indeed, most stated that they cared for adolescent patients up to adulthood, while the remainder discharged patients to adult surgeons without an organised transition procedure. This may be due to the relatively late development of paediatric surgical services in Malaysia, which only saw its expansion in $1990 .{ }^{16}$ Moreover, the demographic distribution of the respondents indicated that the majority of the paediatric surgeons were relatively inexperienced, with less than 10 years of experience in this specialty.

Previous research has stressed the importance of a separate ward for adolescents. ${ }^{19}$ On top of any underlying medical conditions, adolescents also undergo various developmental, social, psychological and sexual changes. As such, the care of adolescents in a hospital setting can be challenging. ${ }^{20,21}$ Adolescent units are usually managed by trained nursing, medical and ancillary staff who understand the specific needs of this group of patients and have facilities designed to promote privacy, peer-to-peer contact, independence, mobility and educational continuity. ${ }^{22}$ Moreover, adolescent wards allow paediatric and adult practitioners to meet, discuss and manage adolescent patients together in a collaborative fashion. However, 
even in more developed countries, many young adults are often still admitted to paediatric care, most likely due to disease complexity, failure of transition planning and the lack of appropriate services within the adult healthcare sector. ${ }^{23}$ These observations show that the implementation of TOC procedures can be challenging worldwide and require careful planning and consideration.

In the present study, the majority of paediatric surgeons felt that they should continue to provide assistance if requested, even after adolescent patients had been transferred to adult care. However, views regarding the appropriate age to initiate TOC were divided. According to Paone et al., the TOC process can be divided into four stages. ${ }^{24}$ In stage 1 (i.e. early adolescence, at approximately 10-12 years of age), the patient and their family should be introduced to the concept of transition and the various processes involved. In stage 2 (i.e. middle adolescence, at approximately 13-15 years of age), the patient should be encouraged to take 'ownership' of their healthcare and the management of their condition. In stage 3 (i.e. late adolescence, at approximately 16-18 years of age), the patient should be introduced to the adult healthcare team and taught independent healthcare consumer skills. Finally, in stage 4 (i.e. young adulthood, at approximately 18-24 years of age), the patient should be discharged from paediatric care and transferred to adult care. ${ }^{24}$ However, further research is necessary to determine whether adoption of this TOC model requires any modification for implementation in local settings in Malaysia.

Effective communication is a key component to a successful transition process. In the current study, most respondents agreed that transfer summaries should be endorsed by a more experienced practitioner such as a consultant or a specialist in order to ensure that relevant information is conveyed to the receiving team. In addition, patients' medical summaries should also be easily accessible by the patient, transition care provider and adult surgeons.

Malaysian paediatric surgeons indicated adult comorbidities to be the most common factor for initiating TOC procedures, followed by a stable disease process, pregnancy, institutional policies and the patient's independence and ability to make their own healthcare decisions. While all of the aforementioned factors are relevant issues that require discussion with the adolescent and their parent during the transition period, the main goal should be to prepare adolescents to independently navigate an adult healthcare setting. Hence, the readiness of the adolescent should be considered the most important trigger for TOC. ${ }^{8}$
Barriers to adequate TOC may differ according to practice setting. A healthcare setting with established transition practices may face barriers such as a lack of adult providers, patient health issues and emotional attachment on the part of the patient to their primary care provider. ${ }^{25}$ In the current study, set in a region where TOC is still developing, the main barriers perceived by paediatric surgeons were related to the lack of proper TOC guidelines, institutional policies and the lack of awareness among healthcare providers. Currently, in light of the growing number of adolescent surgical patients in Malaysia, there is a need to streamline and maintain standards of practice as such patients reach adulthood.

Lack of awareness regarding TOC evidently leads to an absence of guidelines and institutional policies, thereby adversely affecting the development of transition care. Subsequently, paediatric surgeons often have insufficient knowledge regarding this aspect of care and, even if they are aware of the concept, may be only superficially involved in these processes in actual practice. ${ }^{4}$ Furthermore, both paediatric surgeons and paediatricians may be unsure which adult providers are qualified to manage young adults. In turn, patients and their parents may also be unaware of the need for early TOC planning and how to access appropriate adult healthcare services. ${ }^{26}$

A paucity of adult healthcare providers was also highlighted as another major barrier to TOC in the current study. Unfortunately, the general surgeonto-population ratio in Malaysia is still far from that of developed nations. ${ }^{27}$ Adult surgeons in this region may therefore be overburdened by patients and not able to take on the extra workload involved in caring for adolescents. Moreover, adult providers may have insufficient knowledge and training to manage complex health issues in young adults, making it difficult for the patient and their parents to develop a trusting relationship with the adult practitioner. ${ }^{28}$ Nevertheless, the increasing number of paediatric surgeons over the past decade, brought about primarily by the establishment of paediatric surgery fellowship and postgraduate programmes as well as the increase in adult surgery subspecialties, has encouraged the development of TOC facilities. It is therefore likely that the number of adult healthcare providers able to care for adolescent patients will improve with continued collaboration between paediatric and adult surgeons.

In paediatric care, the parents, guardians and/ or close family members of the patient usually play a key role in decision-making, consent and treatment. Furthermore, paediatric practice more commonly emphasises the importance of a child- or youth-friendly 
environment. In contrast, adolescents attending adult clinics are often expected to be solely responsible with regards to consent, their own treatment and personal well-being, with limited time and resources available for counselling. ${ }^{29}$ The change from a more protective and nurturing environment to near complete independence can inhibit and intimidate adolescent patients; as such, appropriate resources and counselling services should be offered so that adolescent patients and their parents can more readily adapt to the adult healthcare environment. ${ }^{30}$ Future research to support the development of TOC in paediatric surgery in Malaysia should investigate various approaches, including the development of registries for paediatric surgical congenital anomalies, guidelines for a successful TOC model and, once established, the continuous monitoring of transition programmes.

This study was subject to several limitations. First, the anonymity of the participants was difficult to ensure in light of the small study population which was further subdivided into groups based on place of practice. Potential respondents might therefore have opted out of the study due to fear of being identified. However, identification numbers were allocated to each respondent and the collection of the questionnaires was performed by a third party to improve the confidence of the respondents. Second, the results of this survey may not represent the full spectrum of opinions among all paediatric surgeons in Malaysia; in particular, there were fewer responses from surgeons based in private hospitals. Third, only paediatric surgeons were included in the study and the opinions of other stakeholders, who are equally important in the development and initiation of TOC procedures (i.e. adolescents, their parents and adult surgeons), were not surveyed. Finally, this preliminary study explored a general overview of TOC practices and perspectives in paediatric surgery, but did not include specific paediatric surgical conditions.

\section{Conclusion}

The current study surveyed paediatric surgeons in Malaysia and found an absence of clear guidelines or policies in place to address TOC issues for adolescents with complex surgical conditions. The results of this study provide a better understanding of transitional care in this region from the point of view of paediatric surgeons. However, further research involving other stakeholders such as patients and adult surgeons is needed to help formulate a suitable and successful transitional care model in this local setting.

\section{CONFLICT OF INTEREST}

The authors declare no conflicts of interest.

\section{FUNDING}

No funding was received for this study.

\section{References}

1. Giuliani S, Decker E, Leva E, Riccipetitoni G, Bagolan P. Long term follow-up and transition of care in anorectal malformations: An international survey. J Pediatr Surg 2016; 51:1450-7. https://doi.org/10.1016/j.jpedsurg.2016.03.011.

2. Daneman D, Nakhla M. Moving on: Transition of teens with type 1 diabetes to adult care. Diabetes Spectr 2011; 24:14-18. https://doi.org/10.2337/diaspect.24.1.14.

3. Jordan A, McDonagh JE. Transition: Getting it right for young people. Clin Med (Lond) 2006; 6:497-500. https://doi. org/10.7861/clinmedicine.6-5-497.

4. Blum RW, Garell D, Hodgman CH, Jorissen TW, Okinow NA, Orr DP, et al. Transition from child-centered to adult healthcare systems for adolescents with chronic conditions. J Adolesc Heal 1993; 14:570-6. https://doi.org/10.1016/1054-139x(93)90143-d.

5. Gortmaker SL, Sappenfield W. Chronic childhood disorders: Prevalence and impact. Pediatr Clin North Am 1984; 31:3-18. https://doi.org/10.1016/s0031-3955(16)34532-1.

6. Robertson LP, McDonagh JE, Southwood TR, Shaw KL; British Society of Paediatric and Adolescent Rheumatology. Growing up and moving on. A multicentre UK audit of the transfer of adolescents with juvenile idiopathic arthritis from paediatric to adult centred care. Ann Rheum Dis 2006; 65:74-80. https://doi. org/10.1136/ard.2004.032292.

7. Heery E, Sheehan AM, While AE, Coyne I. Experiences and outcomes of transition from pediatric to adult health care services for young people with congenital heart disease: A systematic review. Congenit Heart Dis 2015; 10:413-27. https://doi.org/10.1111/chd.12251.

8. Kaufman BA, Terbrock A, Winters N, Ito J, Klosterman A, Park TS. Disbanding a multidisciplinary clinic: Effects on the health care of myelomeningocele patients. Pediatr Neurosurg 1994; 21:36-44. https://doi.org/10.1159/000120812.

9. Shemesh E. Non-adherence to medications following pediatric liver transplantation. Pediatr Transplant 2004; 8:600-5. https://doi.org/10.1111/j.1399-3046.2004.00238.x.

10. Woodhouse C. Adolescent Urology and Long-Term Outcomes. Chichester, UK: Wiley-Blackwell, 2015. Pp. 1-10. https://doi. org/10.1002/9781118844854.ch1.

11. Cabatan MC. Transition related dilemmas of persons with developmental disabilities. Asian J Occup Ther 2013; 3:15-26. https://doi.org/10.11596/asiajot.3.15.

12. Goh DY. Paediatric services: The future direction. Ann Acad Med Singapore 2014; 43:343-5.

13. Jin YT, Chen CM, Chien WC. Factors influencing transitional care from adolescents to young adults with cancer in Taiwan: A population-based study. BMC Pediatr 2016; 16:122. https://doi. org/10.1186/s12887-016-0657-z.

14. Wong LH, Chan FW, Wong FY, Wong EL, Huen KF, Yeoh EK, et al. Transition care for adolescents and families with chronic illnesses. J Adolesc Health 2010; 47:540-6. https://doi.org/10.10 16/j.jadohealth.2010.04.002.

15. Ishizaki Y, Maru M, Higashino H, Katsumoto S, Egawa K, Yanagimoto $\mathrm{Y}$, et al. The transition of adult patients with childhood-onset chronic diseases from pediatric to adult healthcare systems: A survey of the perceptions of Japanese pediatricians and child health nurses. Biopsychosoc Med 2012; 6:8. https://doi.org/10.1186/1751-0759-6-8. 
16. Nor MBM. 39th A M Ismail Oration 2012. A Long Journey of Hope - the Development of Paediatric Surgery in Malaysia. From: www.acadmed.org.my/newsmaster.cfm?\&menuid=68\&par entid=46\&action=view\&retrieveid $=52$ Accessed: Jun 2019 .

17. Narasimman S, Nallusamy M, Hassan S. Review of oesophageal atresia and tracheoesophageal fistula in Hospital Sultanah Bahiyah, Alor Star. Malaysia from January 2000 to December 2009. Med J Malaysia 2013; 68:48-51.

18. Goon HK. Repair of anorectal anomalies in the neonatal period. Pediatr Surg Int 1990; 5:246-9. https://doi.org/10.1007/ BF00169662.

19. Platt H. The welfare of children in hospital. Br Med J 1959; 1:166-9. https://doi.org/10.1136/bmj.1.5115.166.

20. Mackenzie H. Teenagers in hospital. Nurs Times 1988; 84:58-61.

21. Godfrey K. The young ones: Teenagers in hospital. Nurs Times 1998; 94:26-8.

22. Fisher M. Adolescent inpatient units. Arch Dis Child 1994; 70:461-3. https://doi.org/10.1136/adc.70.6.461.

23. Lam PY, Fitzgerald BB, Sawyer SM. Young adults in children's hospitals: Why are they there? Med J Aust 2005; 182:381-4. https://doi.org/10.5694/j.1326-5377.2005.tb06755.x.

24. Paone M, Whitehouse S. ON TRAC: Transitioning responsibly to adult care - Developing a transition initiative for youth and young adults with chronic health conditions and/or special needs in BC. From: www.bcchildrens.ca/transitionto-adult-care/Documents/ON\%20TRACBackground2011.pdf Accessed: Jun 2019.
25. Durkin ET, Zurakowski D, Rangel SJ, Lillehei CW, Fishman LN. Passing the baton: The pediatric surgical perspective on transition. J Pediatr Surg 2015; 50:1196-200. https://doi.org/10.10 16/j.jpedsurg.2014.10.050

26. Lebensburger JD, Bemrich-Stolz CJ, Howard TH. Barriers in transition from pediatrics to adult medicine in sickle cell anemia. J Blood Med 2012; 3:105-12. https://doi.org/10.2147/ JBM.S32588.

27. National Healthcare Statistics Initiative, Ministry of Health Malaysia. National healthcare establishments \& workforce statistics hospitals 2010: Chapter 5 - Surgical services in Malaysian hospitals. From: www.crc.gov.my/nhsi/nhews2010/ Accessed: Jun 2019.

28. Reiss JG, Gibson RW, Walker LR. Health care transition: Youth, family, and provider perspectives. Pediatrics 2005; 115:112-20. https://doi.org/10.1542/peds.2004-1321.

29. Taube-Schiff $M$, Yufe S, Dettmer E, D'Agostino NM, Sockalingam S. Bridging the gap: Patient experiences following transfer of care from a pediatric obesity management program to an adult bariatric surgery program. Bariatr Surg Pract Patient Care 2016; 11:67-72. https://doi.org/10.1089/bari.2015.0048.

30. Gray WN, Schaefer MR, Resmini-Rawlinson A, Wagoner ST. Barriers to transition from pediatric to adult care: A systematic review. J Pediatr Psychol 2018; 43:488-502. https://doi. org/10.1093/jpepsy/jsx142. 